\title{
Time-lapse photography as an effective method for bat population monitoring
}

\author{
David GuiXé $^{1 *}$, Elena Roca ${ }^{1}$, Gerard Barengueras ${ }^{1}$
}

${ }^{1}$ Forest Sciences Centre of Catalonia. Ctra. de Sant Llorenç de Morunys, km 2. 25280 Solsona.

*Corresponding author: david.guixe@ctfc.es

DOI: https://doi.org/10.14709/BarbJ.9.1.2016.02

Spanish title: La fotografía en time lapse como un método efectivo para monitorizar poblaciones de murciélagos

\begin{abstract}
Determining the size of bat populations is essential for evaluating their conservation status. Camera trapping with time-lapse is a rarely used technique but has many potential advantages for monitoring bats. We tested this technique to see if it is an appropriate technique for monitoring bat colonies all-year-round and for surveying the phenology of roosting sites. We sampled a colony of lesser horseshoe bats Rhinolophus hipposideros for a year to assess the efficiency of this method. We estimated that the colony of $R$. hipposideros contained 23-25 adults and 10-14 individuals of juveniles; we determined the arrival time of the colony in March and its departure time in early November, as well as the reproductive periods. Their daily activity patterns during the four seasons were described and consistent with the available literature. We proved this technique as a valuable method for bats survey in a non-intrusive way, making possible to gather valuable information on bats populations.
\end{abstract}

Keywords: activity patterns, camera traps, bat colonies, horseshoe bats, monitoring, population dynamics, time lapse, Rhinolophus hipposideros.

\section{INTRODUCTION}

Camera trapping is a survey method that minimizes observer effects on animal behavior (Swann et al. 2004, Kucera \& Barrett 2011). This non-intrusive method can provide photographic data on the distribution, abundance and habitat use of some species (Mace et al. 1994, Long et al. 2008, Rydell \& Russo 2015). It is a reasonably low-cost technique and is increasingly used in field surveys. Recently, more sophisticated devices have been developed that are capable of capturing instant and high-quality images and videos (Guixé \& Camprodon 2009, Torre et al. 2009).

To our knowledge, few scientific studies have used wildlife cameras traps to monitoring bat colonies (Kunz 2003, Rydell \& Russo 2015, Sedgeley 2012a). In this paper, we assess the effectiveness of camera traps to monitor colonies of the lesser horseshoe bat (Rhinolophus hipposideros). We monitored a colony of this species, estimated its size, and determined year-round activity patterns at the roost.

\section{Materials AND Methods}

A single lesser horseshoe bat colony was selected for study. The colony is situated in a hydroelectric plant of ENDESA S.A. in Orfes (Pla de l'Estany, NE Spain). The colony was surveyed from March 2014 to March 2015.

Two camera traps (Reconyx Rapid fire HD550) were deployed within the roost where bats were present (Fig.1). One camera was placed in a small room with plasterboard ceiling (small room), and the other one in a larger room with brick ceiling (large room). Both rooms were interconnected. We set up the cameras in the most appropriate position to capture the roof area of the two rooms in the photographs (approximately $90 \%$ of the surface of the ceiling). Cameras were programmed in time-lapse mode, i.e. they were programmed to take a picture ( 5 megapixels with infrared flash) every hour from 19 p.m. to 9 a.m. (15 photos per day). We decided to take one picture per hour to control bat activity during their active time (from the evening to early morning). We assumed that movements during day hours will be 


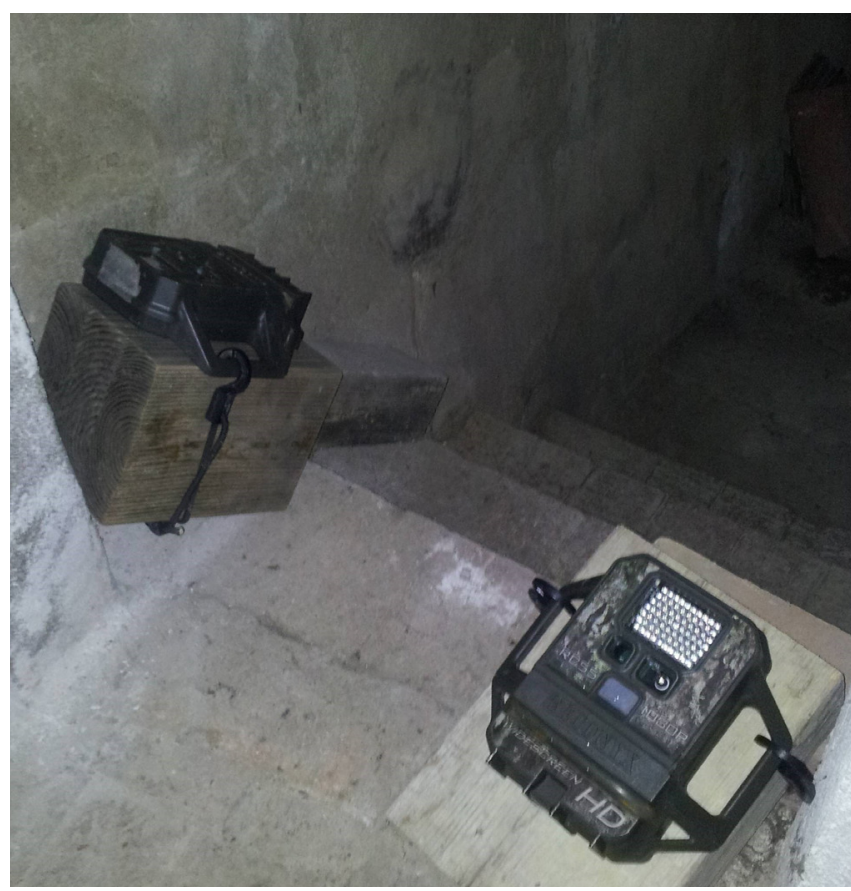

Fig. 1 -Camera traps used to count bats on the ceiling of the small and large rooms.

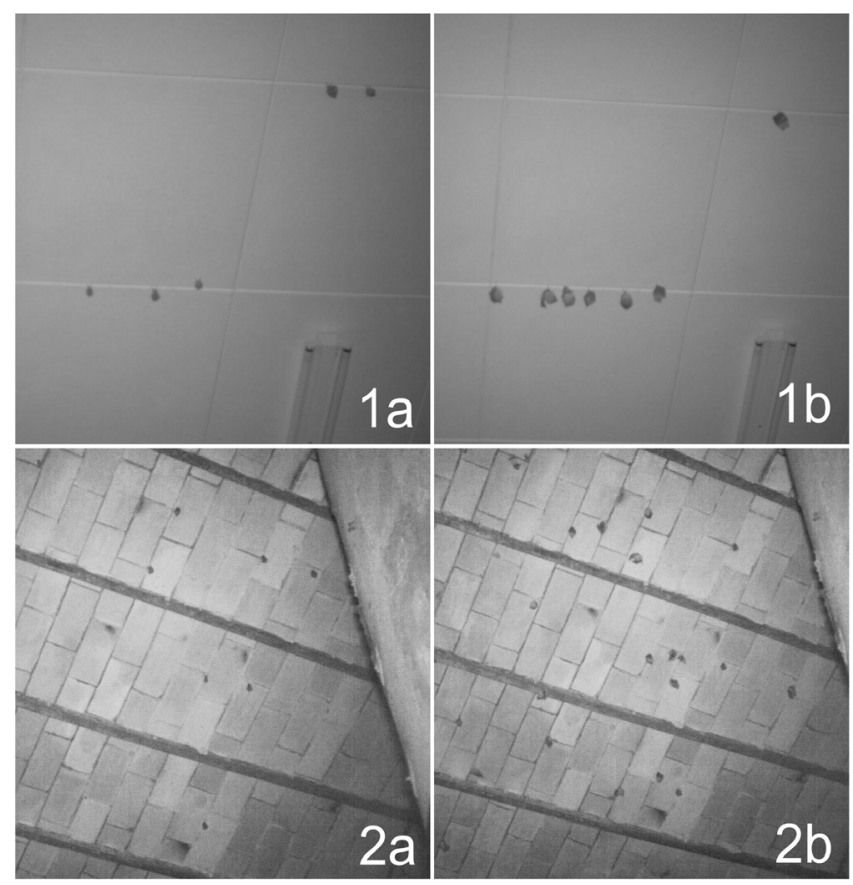

Fig. 2 - Lesser horseshoe bat colony in Orfes (Pla de l'estany), in small room (1) and large room (2) with pups (1a and $2 \mathrm{a})$ and adults $(1 \mathrm{~b}, 2 \mathrm{~b})$ differing in size.

minimal. By reducing the number of photos taken each day we would save battery and consequently we would not need to access the building and disturb the colony so many times to replace them. Cameras functioned properly between $-25^{\circ}$ and $+25^{\circ}$ Celsius, and it was necessary to replace batteries every 4 months. We identified and counted all individuals, and distinguished between adult (full grown) and young (offspring) bats (Fig. 2). To calculate bat abundance, we counted the number of individuals in the ceiling room on each photograph separately using a computer picture's programme.

\section{RESUltS}

In total, we estimated that the colony harboured 23-25 adult lesser horseshoe bats. We observed that the arrival time of lesser horseshoe bats was in March, with 10-12 individuals appearing at this time. From late April to mid of June most of the bats disappeared from the colony. The colony reached its maximum size $(n=48)$ when juveniles were present.

When the first births took place, the small room (with ceiling plasterboard) was used by the colony. Bats also used this room for mating and during the autumn (Fig. 3). In early November, the colony started to move towards the wintering sites and left the building. However, a small number of bats (less than 10 individuals) remained in the rooms during the first two winter months (Fig. 3). During the coldest months (i.e. January and February) almost all bats left the building except 1-2 individuals (Fig. 3).

The first pups were detected on June 23th in the small room and on July 4th in the large room. The latest births were recorded on July 20th (Fig. 4).

Bats were observed giving birth in three periods: the first births concentrated in late June in the small room where the temperature is higher $\left(22-25 \mathrm{C}^{\circ}\right)$. The second breeding period was in mid July in the large room. The last period was in late July with a few juveniles in the two rooms where temperature was similar.

In total, the number of juveniles ranged between 10 and 14 individuals ( $44 \%$ of the estimated number of adults). Juveniles reached the same size as adults after 15 days and were ready to fly around 3-4 weeks after birth (Dietz et al. 2009) (Fig. 4).

This species showed a bimodal pattern of activity, which seems to be related with sunset and sunrise. On average, adults started to leave juveniles alone on the roof at sunset when they began foraging. Some bats returned around midnight to the colony. Later at night, mainly between $3 \mathrm{am}$ and 5:30 am, most adults left the suckling bats by themselves (Fig. 5).

Daily activity pattern in this species was fairly constant along the year (Fig. 6). Bats were inactive during the winter, with limited movements at dusk in the warmest days. In spring bats left the roost for foraging at around $20 \mathrm{pm}$ and returned at around $6 \mathrm{am}$. In summer, during the breeding season, they tended to leave for foraging at around $21 \mathrm{pm}$. A few individuals returned between 1 and $2 \mathrm{am}$, but on average most of them came back to the roost between 5 and 6 am, around sunrise (Fig. 6).

\section{Discussion}

Recent advances in technology have enabled scientists to address important questions about the social life and phenology of bats (Sedgeley 2012a, Rydell \& Russo 2015, Lino et al. 2015). Remote camera traps are a non-invasive method that can outperform traditional methods of visual counts and provide valuable information on the social behavior, phenology, daily movements and activity cycle of bats (Sedgeley 2012b, Lino et al. 2015). The present paper 


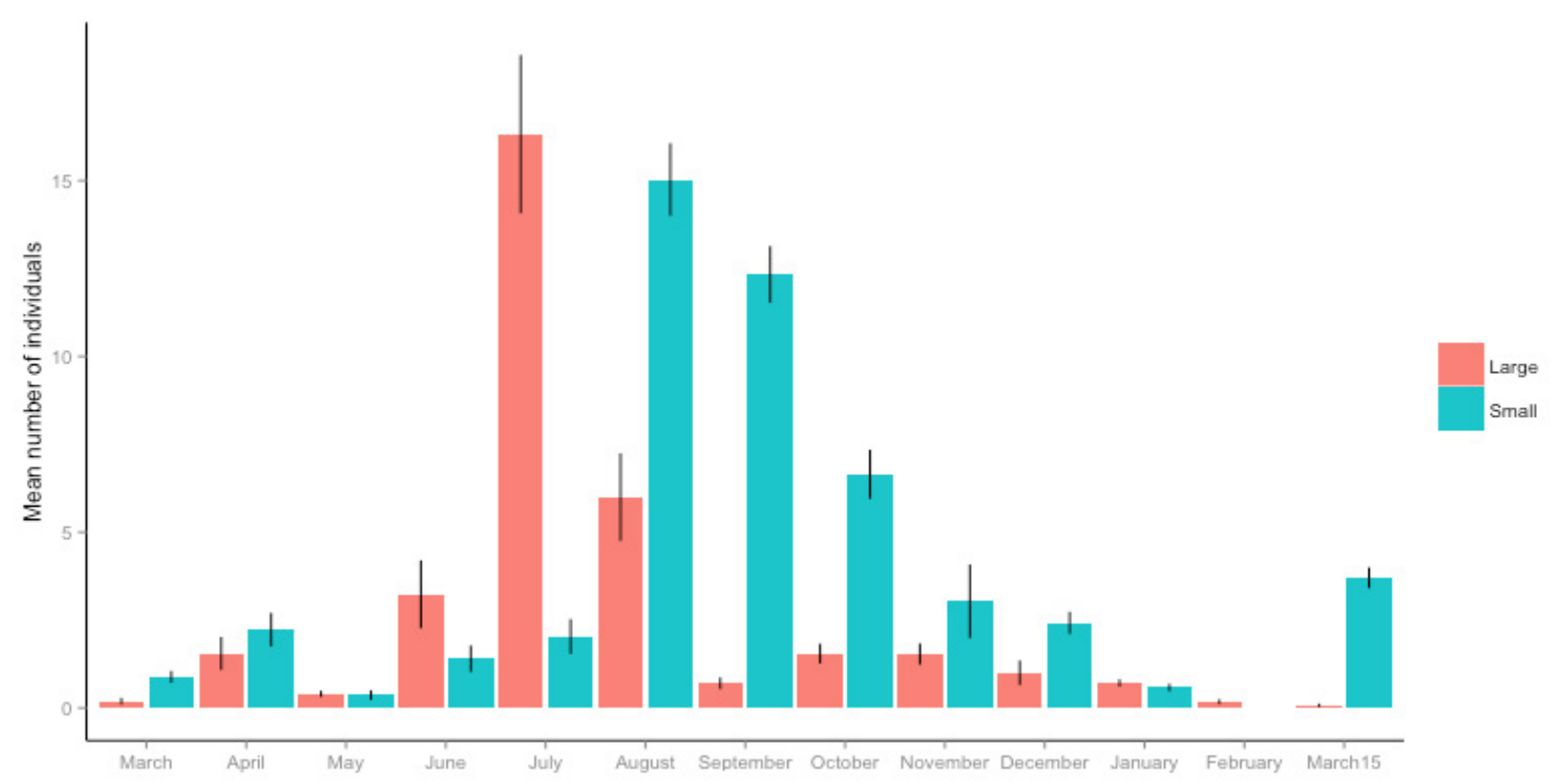

Fig. 3 - Mean and standard deviation of individuals per month in small and large rooms used by the bat colony.

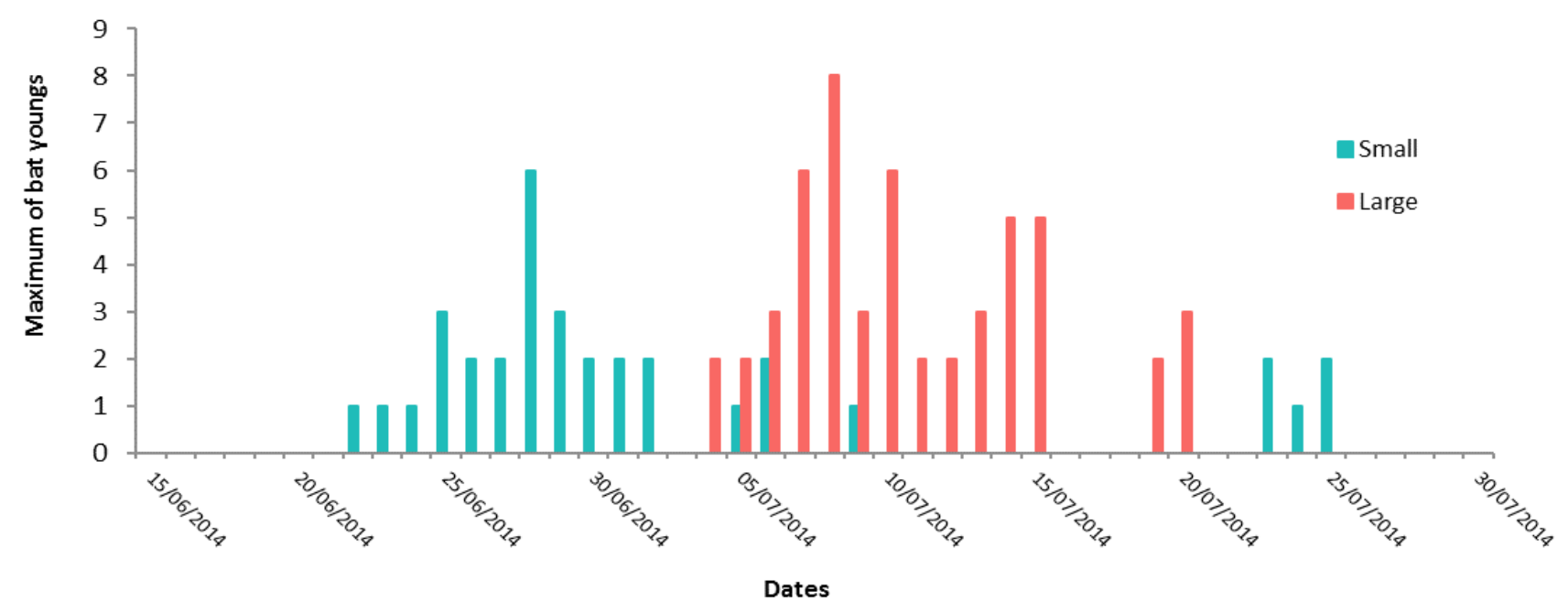

Fig. 4 - Maximum number of juveniles per day in the small and large rooms used by the bat colony.

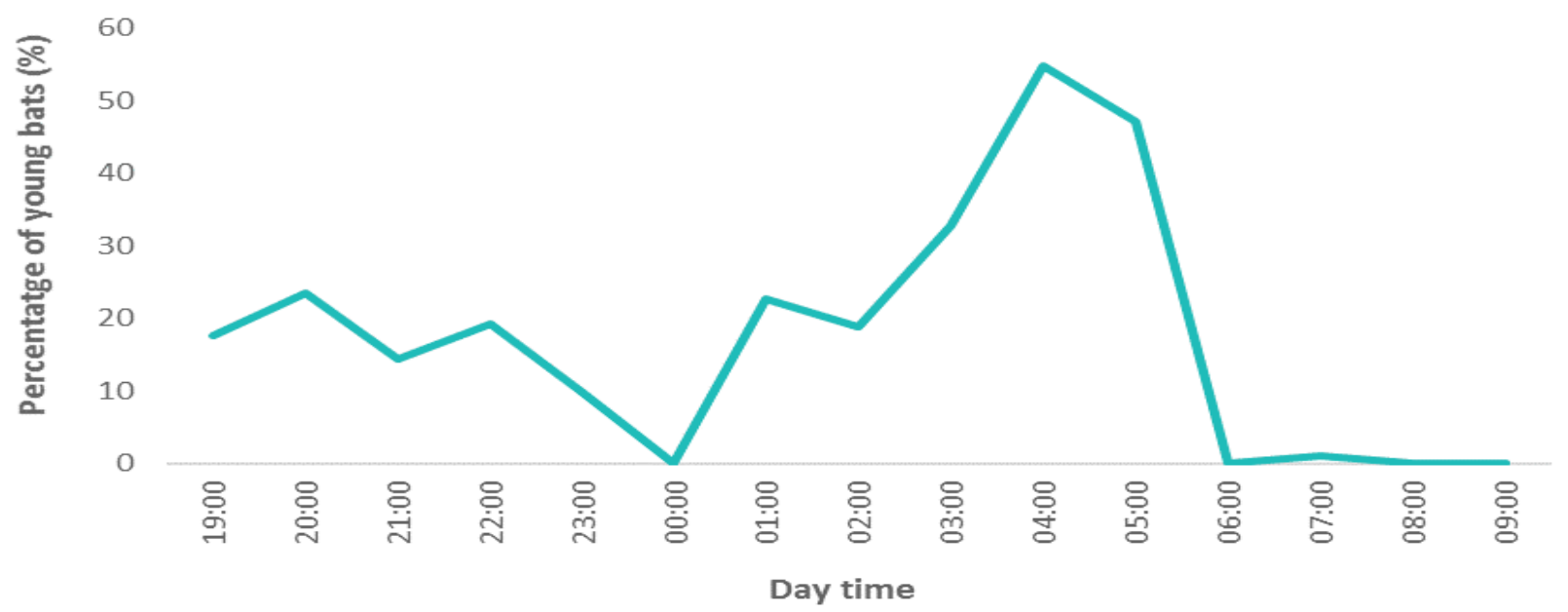

Fig. 5 - Hourly average of young bats that remained alone during the breeding period (from June to late July). 


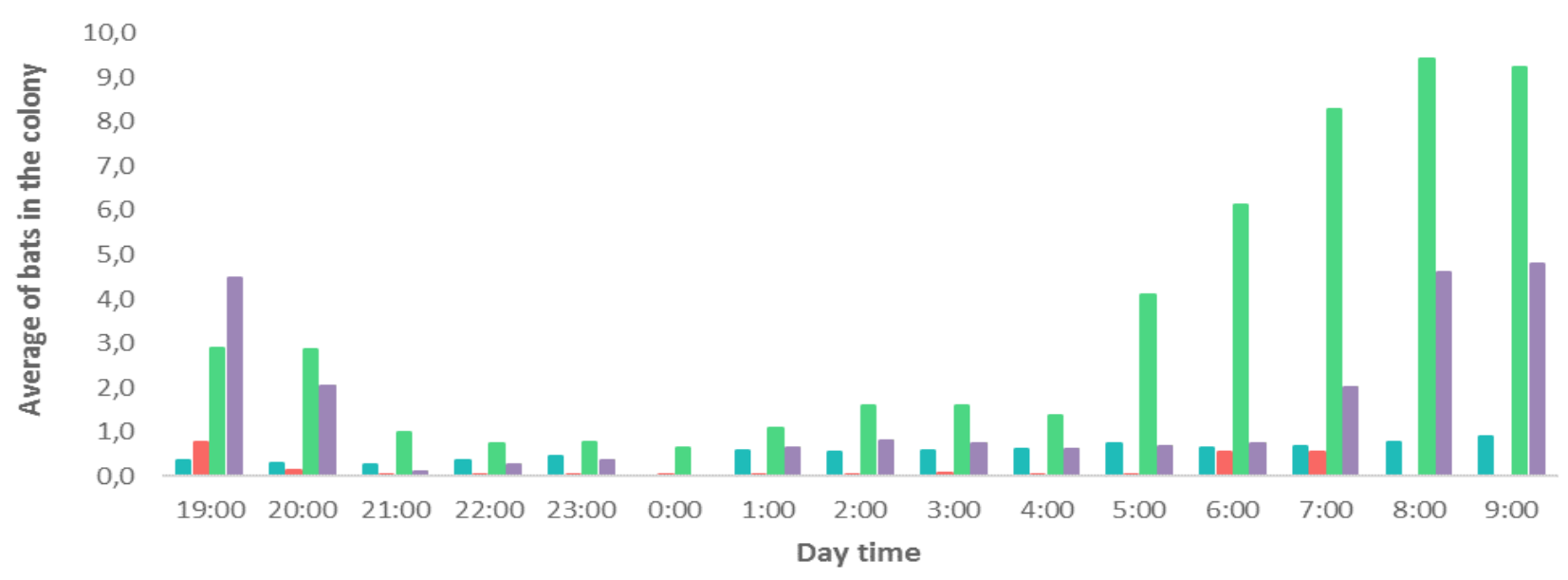

Fig. 6 - Average number of adult bats remaining in the colony between 19:00 and 09:00 during the four different seasons. Spring: red; winter: blue; summer: green; autumn: purple.

provides data about a non-intrusive and novel method to monitor bat populations using time lapse cameras (Rydell \& Russo 2015). We show that time lapse cameras provide valuable and accurate data on the phenology of a small confined colony of the lesser horseshoes bat. Our method is most suitable for roof hanging bats. Limitations of this method include the large effort required to check many photographs and the necessity of having several cameras, setup at the correct angles, to simultaneously cover large roosts.

Using camera traps increased our knowledge of the mating period of lesser horseshoe bats and provided accurate information about birth rates. This information can be used to plan future surveys and to determine the most appropriate period to undertake counts at roosts using other methods (Sedgeley 2012a).

Normally, after the winter, females are known to arrive before males at the breeding roosts (Dietz et al. 2009). In our case, we noted that they arrive in March, but from late April to mid June most bats disappear from the roost. A productive area for future research would be to examine whether bats return to an intermediate shelter before giving birth in late June, as described in other locations (Schofield 1996, Reiter 2004, Ifrim 2007). Rhinolophids exhibit a long gestation period and long lactation period (Schofield 1996, SerraCobo et al. 2008) and require undisturbed areas at least from June to end of July (Dietz et al. 2009). The number of pups produced by the colony was around $44 \%$, slightly higher than described in Schofield (1996).

The first juveniles appeared in the small and hotter room, indicating that temperature might play an important role in the timing of reproduction (Lucan et al 2013). This species positively selects warm roosts during the lactation period (Schofield 1996, Lino et al. 2015), which may be the reason why they first gave birth in the small room. Later, during the season when temperatures were similar between the two rooms, females also gave birth in the larger room. However, it is also possible that females moved tothe large room during the mating season, because of its rougher ceiling surface, where it is easier for young bats to hang.
In early November, the colony started to leave the roost, probably moving towards the wintering sites. This species usually uses caves or underground mines at this time, where they find more suitable temperatures and higher relative humidity in which to hibernate (Serra-Cobo et al. 2008, Dietz et al. 2009). Nearly all animals left the roost except for two individuals that remained all winter long in the large room, probably because the temperature was colder than in the small room.

In terms of nightly activity, rhinolophids usually leave the roosts early after sunset and return late, actively hunting almost all the night. Females tends to return early, particularly reproductive females that are suckling their young. Early returns correlate with the coldest hours of the morning. The relative amount of time spent roosting and foraging during the night vary both daily and seasonally in relation to the reproductive condition of the bats. Prey density and ambient temperature are also strong influences on the timing of foraging (Anthony et al. 1981). As already reported for lesser horseshoe bats, roosting time reach a maximum in late summer before juveniles could fly and when they remained in shelter (Anthony et al. 1981, Lino et al. 2015). Most adults return late at night (around $6 \mathrm{~h}$ ), especially in autumn, perhaps to attract females around the shelters (Schofield 1996).

\section{Conclusions}

Camera trapping with time-lapse is a rarely used technique but has many potential advantages for monitoring bats. It is an appropriate method for monitoring bat colonies all-year-round, and for surveying the phenology of particular roosts. It is a valuable method for surveying offspring, since adults leave them hanging by themselves for part of the night, thus making it possible to gather valuable information on population productivity.

Continuing to monitoring lesser horseshoe bats over a larger number of years, covering a range of inter-annual variation, will greatly improve our knowledge of bats phenology and their behaviour. 


\section{ACKNOWLEDGEMENTS}

We thank to ENDESA for their interest and help. We would also like to thank the directives and workers who have helped us throughout the study. We specially thank the assistance of: Toni Palau, Carles Montserrat, Maria Inmaculada Ordoñez and Nines Marin. Thanks to the responsibles of the area: Javier Martínez, Xavier Jou, Joan Palau, Ricard Joval, Jordi Rabionet, Fernando Rivera, Gerard Guàrdia, Carles Zamora and Albert Planagumà.

We appreciate the assistance of Laura Torrent, Marina Talló and Guillem Vilà during the fieldwork, and to all the colleagues of the Biodiversity Department at the CTFC, specially to Luke Kelly and Nicolas Titeau for the English revision. We also thank the two anonymous reviewers for their constructive suggestions and comments.

\section{REFERENCES}

Anthony E. L. P., Stack M. H. \& KunZ T. H. 1981. Night roosting and the nocturnal time budget of the little brown bat, Myotis lucifugus: Effects of reproductive status, prey density, and environmental conditions. Oecologia 51 (2): 151. DOI: http://dx.doi.org/10.1007/BF00540593

Caughley G. 1977. Analysis of Vertebrate Populations. London: John Wiley \& Son. DOI: http://dx.doi.org/10.1002/ bimj.4710190520

Dietz, C., Nill, D., Helversen, O. von, Lina, P.H.C. \& Hutson, A.M. 2009. Bats of Britain, Europe and Northwest Africa. London: A\&C Black. pp: 398

Guixé, D. \& Camprodon, J. 2009. Els quiròpters a Catalunya: noves aportacions a la seva ecologia i conservació. Rural \& Forest 10. CTFC.

IFRIM I. 2007. Nursery colony of Rhinolophus hipposideros (Bechstein, 1800) (Mammalia: Chiroptera) from Vanatori-Neamt Natural Park (Romania). Travaux du Muséum National d'Histoire Naturelle «Grigore Antipa». pp: 355-362.

KUCERA, T.E. \& BARRETT, R.H. 2011. A History of Camera Trapping. pp: 9-26. In: (O'Connell AF, Nichols JD, Karanth KU, editors. Camera Traps in Animal Ecology. New York: Springer)

Kunz, TH. \& Fenton, M.B. (editors) 2003. Bat Ecology. University of Chicago Press, Chicago, Illinois. Pp: 779. ISBN 0-226-46206-4. DOI: http://dx.doi.org/10.1644/15451542(2004)085<0366:BE >2.0.CO;2
Lino, A., Fonseca, C., Mendes, G. \& Ramos, M. 2015. Roosting behaviour and phenology of the Lesser horseshoe bat (Rhinolophus hipposideros) in a breeding colony in Sintra, Portugal. Galemys 27: 1-12. DOI: http://dx.doi. org/10.7325/Galemys.2015.A1

Long, R.A., MacKaY, P., Zielinski, W,J. \& RaY, J,C. 2008. Noninvasive Survey Methods for Carnivores. Washington DC, USA: Island Press.

Mace, R. D., Minta, S. C., Manley, T. L. \& Aune, K. E. (1994). Estimating Grizzly bear population size using camera sightings. Wildlife Society Bulletin, núm. 22, p. 74-83.

Reiter, G. 2004. Postnatal growth and reproductive biology of Rhinolophus hipposideros (Chiroptera: Rhinolophidae). Journal of Zoology, 262: 231-241. DOI: http://dx.doi.org/10.1017/S0952836903004588

Rydell, J. \& Russo, D. 2015. Photography as a lowimpact method to survey bats. Mammalian Biology 80: 182184. DOI: http://dx.doi.org/10.1016/j.mambio.2014.11.003

SCHOFIELD, H.W. 1996. The ecology and conservation biology of Rhinolophus hipposideros, the lesser horseshoe bat. University of Aberdeen.

Sedgeley, J. 2012a. Bats: exit counts at roosts. Cameras and recorders. Version 1.0. In Greene. T, McNutt. K. (editors) 2012. Biodiversity Inventory and Monitoring Toolbox. Department of Conservation, Wellington, New Zealand.

SedGeley, J. 2012b. Bats: counting inside roosts. Version 1.0. In Greene. T, McNutt. K. (editors) 2012. Biodiversity Inventory and Monitoring Toolbox. Department of Conservation, Wellington, New Zealand.

Serra-Cobo, J., M. Lopez-Roig, X. Bayer, B. Amengual \& C. Guasch. 2009. Ratpenats. Ciència i mite. Publicacions i edicions Universitat de Barcelona. pp 267.

Serra-Cobo, J., Sanz-Trullen V. \&. Martinez-Rica J. P. 1998. "Migratory movements of Miniopterus schreibersii in the north-east of Spain." Acta Theriologica 43(3): 271-283.

Swann, D.E., Hass, C.C., Dalton, D.C. \& Wolf, S.A. 2004. Infrared-triggered cameras for detecting wildlife: an evaluation and review. Wildlife Society Bulletin 32: 357-365. DOI: http://dx.doi.org/10.2193/0091-7648(2004)32[357:IC FDWA]2.0.CO;2

Torre, I., Ribas, A. \& Arrizabalago, A.. 2009. Estudio de la Comunidad de Carnívoros del P.N. del Montseny (Catalunya) mediante Trampeo Fotográfico. Galemys 21:165-180. 